\title{
Assessing Self-Directed Learning Readiness among Medical Staff in King Fahad Medical City
}

\section{Mansour Alfadhel ${ }^{1 *}$, Majed K Al-Zahrani ${ }^{2}$, Wa'el Al-Anzi ${ }^{3}$ and Raheel Al-Surayye'a ${ }^{4}$}

${ }^{1}$ Director of Continuous Professional Development Administration, Academic and Training Affairs, King Fahad Medical City, Riyadh, Saudi Arabia

${ }_{2}^{2}$ Medical Students, Al Taif University, Saudi Arabia

${ }^{3}$ Medical Student, Alfarabi Colleges, Saudi Arabia

${ }^{4}$ College of Pharmacy, Al Qassim University, Saudi Arabia

*Corresponding Author: Mansour Alfadhel, Director of Continuous Professional Development Administration, Academic and Training Affairs, King Fahad Medical City, Riyadh, Saudi Arabia.
Received: March 16, 2020

Published: May 14, 2020

(C) All rights are reserved by Mansour

Alfadhel., et al.

\begin{abstract}
Self-directed learning is an essential form of adult learning. It has been recommended as a promising methodology for lifelong learning in healthcare practice. The Self-directed learning tools allow the participants to identify their strengths and weaknesses in areas of self-directed learning. This study was performed to determine KFMC medical staff readiness for self-directed learning and how this is associated with the demographic factors affecting the readiness.

Keywords: Self-Directed Learning; Lifelong Learning; Adult Learning
\end{abstract}

\section{Introduction}

The world of modern healthcare sector is an ever-changing field, which requires in this type of organization to cope with its rapid change. Self-directed learning (SDL) is one of the vital areas as a method of learning in healthcare professional education. Over the past few years, the demand for rapid change in healthcare has led to the dramatic explosion in the healthcare related knowledge and information.

Malcolm Knowles defines self-direct learning as "a process in which individuals take the initiative, with or without the help of others:

- In diagnosing their learning needs.

- $\quad$ Formulating learning goals.

- Identifying human and material resources for learning.

- Choosing and implementing appropriate learning strategies.

- Evaluating learning outcomes" [1].

The tertiary academic healthcare institutions are potential arena for self-directed learning. These educational institutions offer various methods of learning and education to their healthcare workforce, which may include distance learning, blended mode, and e-learning modules, so that the self-directed learning could be utilized as a methodology for lifelong learning in adult education especially in healthcare learning workplace.
King Fahad Medical City (KFMC) is a tertiary healthcare organization in Saudi Arabia that provides specialized healthcare. KFMC is an accredited teaching institution for medical and allied healthcare workers. Continuing education is being conducted at KFMC through traditional and nontraditional methods of presentations by conducting national and international medical conferences as CME's.

This study aims to identify the level of Self-directed Learning Readiness Scale (SDLRS) among healthcare employees working in King Fahad Medical City and to find the association between the level of SDLRS, with gender, specialty, year of experience and academic degree.

A review of published studies on self-directed learning in the healthcare field shows significant number of studies presented that self-directed learning for undergraduate students, and few were conducted on a healthcare professional in hospital settings. Moreover, very few of these published studies were done in Saudi Arabia. The following literature review was categorized based on the following topics.

SDLR among healthcare professionals

- $\quad$ Alwadie [2] examined the readiness of King Fahad Medical City in Riyadh, Saudi Arabia, to adopt online education. Study shows that employees are motivated to learn online, and their technical skills are acceptable and suggestive of success. 
- In 2012 Lucia Cadorin., et al. [3] conducted a cross-sectional study to assess the self-directed learning competence in groups of healthcare professionals, registered nurses (RNs) and registered respiratory therapists (RTs), as well as in two samples of bachelor students. The results show minimal differences in self-directed competence between RNs and RTs, and some can also be found amongst students.

- $\quad$ Tahere and Nouzar [4] had identified the factors influencing the medical doctors' self-directed learning readiness for elearning. The most important factors that learners identified in their study were; familiarity, independent study, innovativeness, the relevant and applicable subjects, self-evaluation, selfdevelopment, self-discipline in learning, and self-motivation.

- Jolij's [5] study, shows that Self-direct learning teamwork can play a role in the professional development of healthcare professionals and the most highlights in this research is that the level of team learning behavior is not associated with the extent to which team members are self-directed in their learning. A cross-sectional survey that was conducted in his research it measures the effect of Self direct learning teamwork and Team learning behavior on SDL in a healthcare organization providing support for people with mental and/or physical disabilities.

SDLR among students in medical and health colleges

- $\quad$ Badshah., et al. (2015) conducted a cross-sectional study in which the majority of students have a positive attitude toward self-directed learning, and they have an adequate level of self- directed learning readiness.

- William's., et al. [6] has mentioned in his study also the positive result regarding SDLRS in paramedic students. There were differences detected between participating universities, indicating that different teaching methods may hold a role in SDL readiness. Moreover, other factors such as learning or personality styles may also influence SDL readiness as might student's pathway into tertiary education.

- Most of the literature used one discipline: medicine $[7,8]$; nursing $[9,10]$; pharmacy $[11,12]$ and dentistry [13]. A few studies used multidisciplinary as sample size $[14,15]$. So, this study will fill a gap in the area of self-directed learning of the different healthcare professionals in a tertiary educational hospital in Saudi Arabia.

- The results of this study on SDLR can contribute to a better understanding of health workers self-directed learning readiness at the workplace and to support the education and learning developer in charge to take in consideration the level of health workers self-direct learning and their preferences when they design and conduct educational activities.

\section{Study Methodology}

This study employed a survey research methodology. Data was collected using Guglielmino's self- directed learning readiness (SDLR) scale covering the demographic features of participants and the eight factors that define attitudes, values, and abilities of adult learners associated with readiness for self-directed learning.

\section{Study area}

The research was conducted among the health professionals at a large healthcare organization in Saudi Arabia.

Study subjects and population

- Inclusion criteria: All healthcare employees who have directly or indirectly contact with patients.

- $\quad$ Exclusion criteria: All KFMC administrative employees.

Study design

A Cross-sectional descriptive study.

\section{Sampling technique}

All the eligible listed employees were recruited through proportional stratified random sampling.

\section{Sample size}

Sample size $(\mathrm{N})=95 \%$ confidence interval (1.96) with standard deviation $2 \div$ error rate.

\section{Data collection methods}

The information was gathered by an online survey questionnaire.

\section{Instruments used}

The best well-known assessment associated with SDL, the Self-directed Learning Readiness Scale (SDLRS) developed by Guglielmino [16] was used for this study. According to Merriam, Caffarella and Baumgartner [17], the SDLRS is the most extensively used assessment instrument within the field of SDL. Guglielmino developed the tool as a way to effectively measure the complexities of the characteristics that define the readiness to participate in selfdirected learning [16,17].

The survey has five demographic questions. An informed consent form will be filled by each participant. Once consented, the participant will be asked to fill in the demographic information and subsequently answer the SDLRS questionnaire. All healthcare workers' personal information are kept confidential.

\section{Scoring system}

Self-directed Learning Readiness Scale (SDLRS), which measures a person's readiness to be self-directed is a 58-item, 5-point Likert scale ranging from 1 (I hardly ever feel this way), 2 (Not often true of me), 3 (Sometimes true of me) 4 (Usually true of me) to 5 (almost always true of me). 


\section{Statistical analysis}

Data analyses were conducted using the Statistical Package for Social Sciences (SPSS*). The researcher used different analyses for the quantitative statistics in this study. Descriptive statistics such as means and standard deviation (mean \pm SD) were computed to summarize the quantitative variables (SDLRS), while frequencies and percentage, was computed to summarize categorical variables (gender-specialty-academic degree-years of experience).

ANOVA and t-test will be performed to assess the relationship between the SDLRS and demographic factors such as gender, specialty, academic degree, and experience. To find the correlation between each of these factors and the overall SDL score. P value < 0.05 was considered statistically significant.

The Institutional Review Board (IRB) from King Fahad Medical City reviewed and approved this study, with the number: *IRB Log Number: 18-315.

\section{Procedures}

After the necessary approvals were obtained, the survey was presented to the target population, with an explanation and instructions about the purpose of this study. In the direction, it was explained what kind of learning experiences and activities one could think of. Moreover, they were told to include all sort of learning and education when they answered this survey.

In this study, the distribution of the survey was conducted in two phases. First, participants received the hard copy of the survey form by hand. After a few days, an email was sent to them with a link, so they can complete the survey online if they want to do so. In addition to the link in their personal e-mail address, a copy survey was also available with the secretary of each department. The main reason for these options of access to the survey, is to encourage more response and this data collection method would give the least chance of data loss, Moreover, data could be transmitted directly to the analysis program. As a result of this technique, it could be that more people eventually participate and fill the survey of learner and their level of SDLR level.

\section{Results}

The purpose of this study was to determine the level of self-directed learning readiness for the healthcare professional working at King Fahad Medical City in Saudi Arabia using Guglielmino's scale. In addition to that, the study aimed to investigate whether there are statistically significant relationships between the demographic variables (gender, specialty, academic background, work experience), and readiness for self-directed learning.

\section{Participants}

Out of seven hundred (700) surveys that were distributed to all healthcare departments at KFMC, three hundred thirty-six (336) responded which is $48 \%$ of the total target population. With this number of respondents, one (1) did not complete the survey. This response rate is aligned with the response rate of AlFaifi [18]

\begin{tabular}{|c|c|c|}
\hline & Number & Percentage \\
\hline Total Sent & 700 & \\
\hline Responded Surveys & 336 & $48 \%$ \\
\hline Completed & 335 & $47.8 \%$ \\
\hline Uncompleted & 1 & $.0014 \%$ \\
\hline
\end{tabular}

Table 1: Return Rate of the participants at KFMC.

(45\%) and AlWadie [2] (49\%). Table 1 summarizes the distribution and returns rate of the participants' surveys.

\section{Employees' demographics}

Of the participants 101 (30.1\%) were male and 234 (69.9\%) were female. Respondents included 62 (18.5\%) physicians, 16 (4.8\%) pharmacists, 185 (55.2\%) nurses and 72 (21.5\%) allied health.

Almost half of the respondents which is $49.85 \%$ (167) were between 20 and 30 years of age, while only 29\% (98) were between 36 - 45 years of age. Table 2 shows the demographic variables of all participants.

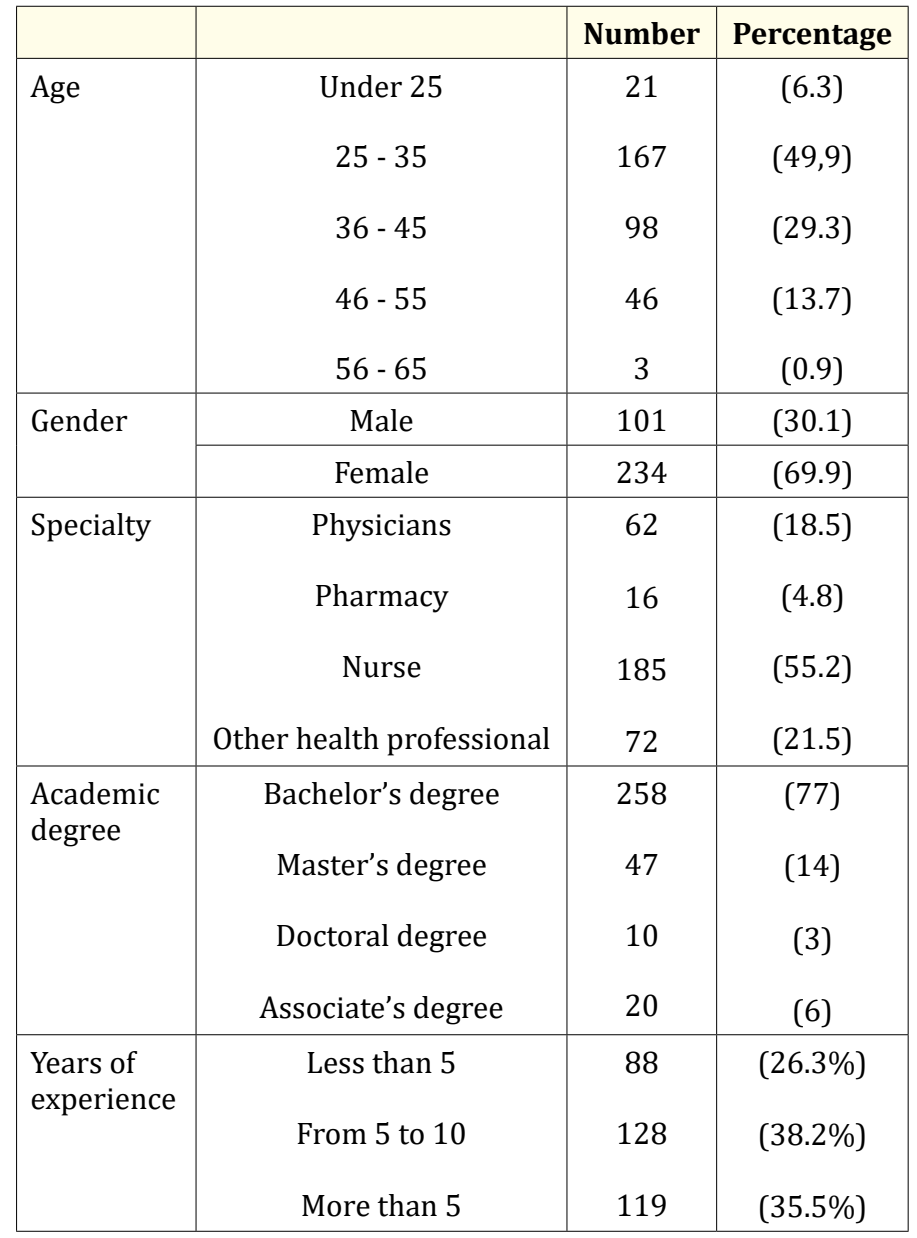

Table 2: Participants' demographic variables at KFMC.

The respondents' SDL level was measured with the five-point Likert-scale of Guglielmino, results revealed that the participant's total SDLRS scores ranged from min. 115 to max. 278 with a mean score of 223 and a standard deviation of 22.66. This means that the 
self-directed learning reediness of KFMC's health care professionals was of average level (See table 3).

\begin{tabular}{|c|c|}
\hline \multicolumn{2}{|c|}{ Group Statistics } \\
\hline Mean & 222.9107 \\
\hline Variance & 513.8116 \\
\hline Standard deviation & 22.66741 \\
\hline Standard error & 1.236609 \\
\hline Minimum & 115 \\
\hline Maximum & 278 \\
\hline
\end{tabular}

Table 3: Descriptive Statistics for SDLRS Scores of the overall of all participants.

An independent $t$ - test was performed to determine if there was a significant difference between the level of SDLRS and the gender. The result of t-test indicated that there was no significant result, $p$ $=0.150$ between the level of SDLRS and gender. These results suggest that gender did not have any significant influence on the level of self-directed learning readiness (SDLR) (Table 4).

\begin{tabular}{|c|c|c|c|c|c|}
\hline Gender & $\mathbf{n}$ & Mean & SD & T (2-tailed) & P \\
\hline Male & 101 & 220 & 23.69 & .623 & .150 \\
\hline Female & 234 & 221 & 21.9 & .635 & \\
\hline
\end{tabular}

Table 4: Independent $t$ test result for gender.

To analyze a possible relation with personal background variables, Analysis of Variance (ANOVA) test was calculated to predict participants' SDL attitude based upon their years of work experience, educational level, and specialty. The result of the one-way ANOVA found that none of the demographic variables contributed significantly to the variance associated with readiness for selfdirected learning. However, the relationships between associate degree and master degree as well as between master degree and bachelor degree holder were significant (.012) (.001) respectively. The result of the ANOVA test is shown in table 5.

\begin{tabular}{|l|c|c|c|}
\hline & & Mean & SD \\
\hline Specialty & Physician & 223.63 & 28.157 \\
& Pharmacist & 217.19 & 25.409 \\
& Nurse & 219.50 & 21.482 \\
& Allied health & 223.10 & 19.025 \\
\hline Academic & Bachelor's Degree & 219.47 & 22.883 \\
Degree & Master Degree & 230.81 & 19.325 \\
& Doctoral Degree & 222.20 & 19.013 \\
\cline { 2 - 2 } & Associate Degree & 215.85 & 22.213 \\
\hline
\end{tabular}

Table 5: Mean and standard deviation for SDLR by subgroup.

\section{Discussion}

In the framework of continuing medical education, which is becoming more and more important to maintain, develop, or increase knowledge, or professional performance standards of healthcare professionals, the ultimate goal is to provide better health care for patients.

The previous studies were not in full consensus regarding the relationship between the personal demographic characteristics and the SDL, as some of these studies $[19,20]$ sported the positive relation between one or more demographic factor and the self- direct learning. However, the present study revealed that there was no significant difference between demographic characteristics with the overall score of self-directed learning readiness, and this result is in line with other studies where the self-directed learning is not influenced by the demographicfactors [21].

Although the demographic variables are important, the variation between the studies that reported the existing or non-existing relationship between the demographic factors and SDL indicates that the demographic factors may have different effects in diverse situations. Accordingly, this outcome guides the health professional educationists to design their learning and training for the healthcare professionals in such a manner that it takes into consideration the target audience's basic personal factors such as age, gender, year of experience, etc.

On the other hand, this study involved a quite good number of healthcare workers aiming to maintain progress by identifying the level of self-directed learning. As e-healthcare sector is one of the busiest work areas among other professionals, and they are always overwhelmed with their daily tasks, so it was predicted that the level of self-direct learning would be having an average score (223) among the health professional targeted by this study. This means that the self-directed learning reediness of KFMC's health care professional is of average level. Guglielmino [16] interpreted each individual's SDLRS score based on her sample as follows.

\begin{tabular}{|c|c|}
\hline Readiness Level & SDLRS Scores \\
\hline Low & $58-176$ \\
\hline Below Average & $177-201$ \\
\hline Average & $202-226$ \\
\hline Above Average & $227-251$ \\
\hline High & $252-290$ \\
\hline
\end{tabular}

Table

According to Guglielmino, people who score average are not comfortable with entirely maintaining their own learning strategies and methods; they would prefer to be in an independent setting.

However, this result can be explained by the adult learning theory which states that the adult (healthcare professionals in this particular study) relies on the accumulated experiences gathered from established procedures and processes as an increasing resource for learning [1]. Moreover, employees in general, sidestep from gaining new information to avoid any change to their daily work that could be hard for them. 


\section{Supports self-directed learning}

Nevertheless, understanding the nature of healthcare settings and the healthcare professionals that serve those areas and in order to adequately address their needs, the healthcare academic institutes must support those professional to cope with these changes; mechanisms should be considered to develop in place targeted towards improving healthcare environment to contextual and embedded the lifelong learning to be part of the individual's daily practice of the healthcare professional. Such reflective practice mechanism will create sense of necessities that healthcare workers require continued education and professional development in order to ensure the delivery of safe, quality services. This educational lifestyle obligatory directed healthcare professionals are proactive in their own self-directed learning and education.

Develop learning objectives and methods based on the learner's needs and interests

An example for the actions that are recommended to be taken by the healthcare institutions to create a culture of self-directed learning is to involve the healthcare professionals to provide flexible, and accessible tools that support and enhance SDL behaviors at the workplace. This is in the same context with the adult learning theory that indicates the adult need to be involved in the planning and evaluation of their instruction [1]. This involvement could be in developing an educational needs assessment, building a development individual educational plan for the employees, as well as education to be customized to individuals.

Conduct a variety of learning activities that excite and motivate the participants

SDL has long been recognized as an essential tool for individual to achieve their educational needs and goals, so creating a capacity for and commitment to SDL is very crucial for the healthcare practitioners, to this end the healthcare educationist advised to have more motivated and encouraged multiple learning strategies and plans to nontraditional educational methods such as collaborative, inter-professional, online platforms, hybrid, and simulation/augmented reality. In addition to that, the passive technique of teaching and learning such as didactic lectures could be replaced by new teaching skills such as the flipped classroom.

\section{Inter-professional partnerships}

In addition to that, the educational activity that delivers to the healthcare professional to be patient- focused. As many other professions such as health educator, social workers, and other professionals have a long history of working with patients in teaching and learning. So as more as the involvement of patients \& family representatives in either designing or delivery of learning and training event will link the healthcare professionals with their daily practice - the adult learning theory specifies that adults are interested in learning subjects that have direct relevance and impact on their job or personal life [1]. Moreover, as a result of patient involvement will lead to more patient safety and better outcomes which will inspire healthcare professionals in the direction of change adaptability rather than change resistance.
Create a climate that challenges learners' assumptions and deepens their critical thinking

Finally, to ensure more involvement of continuing medical education to the healthcare professional daily practices, the healthcare academic institutes need to encourage and support ongoing research and scholarship interrelated continuing medical education tied to patient safety and health care quality outcomes. This movement not only to create an education and learning environment, but also to discover and resolve any obstacles that could hinder engagement of the workforce with the education and learning that their institution creates especially for them. Furthermore, this research study will foster understanding the healthcare professionals' preference learning style which encouraged them to select from the broader range of learning opportunities that they are most likely to enjoy and learn from [22-24].

\section{Conclusion}

We think that this study is a good way to look at the level of self-directed learning in the healthcare workplace. However, further study can be conducted to measure the employees' level of SDL behavior and the relation with their SDL attitude and learning style, and that to disclose more in-depth information of SDL at the workplace. In addition to that, we recommend utilizing the qualitative research methods to explore other influencing factors on SDL.

\section{Limitation of the Study}

This study included the following limitations, which could influence the results or generalizability of the research. The first limitation was this study was conducted at King Fahad Medical City, so that the results might be not be generalizable to other tertiary hospitals in Saudi Arabia. Not all demographic factors were included in this study as the healthcare professional employees in King Fahad Medical City specified only by gender, specialty, academic degree and experience.

Several studies on this topic that were done in KFMC, had helped in laying a foundation for understanding the research problem being investigated. This study will add to the literature on SDLR and especially the studies were done in Saudi Arabia, to explore the SDLR for health workers in the tertiary healthcare organization. In addition to that, this study will examine the correlation between specific factors such as gender, specialty and academic degree with the SDLR level. As a result of this study, it should help to plan and promote the educational process based on the level of SDLR as well as the other factors that affected the learning initiatives and motivations of the healthcare workers.

In addition to that, it could provide a reliable basis for formulating and developing specialized learning strategies and packages that will take into consideration the type of learner and their level of SDLR. 


\section{Bibliography}

1. Knowles MS. "Self-directed learning”. New York: Association Press (1975).

2. Alwadie AD. "An Assessment of the readiness of King Fahad Medical City, Saudi Arabia, in adopting effective online staff development programs". (Doctoral dissertation) (2011).

3. Cadorin L., et al. "The Self-Rating Scale of Self-Directed Learning (SRSSDL): A factor analysis of the Italian version". Nurse Education Today 33.12 (2013): 1511-1516.

4. Eslaminejad T and Nakhaee N. "Self-Directed Learning Readiness Factors in Physicians for Implementing E-Learning in the Continuing Medical Education Programs". In E-learning-Engineering, On-Job Training and Interactive Teaching (2012): 39-46.

5. Jolij EP. "Self-directed learning in self-directed teams in a healthcare organization". (Master dissertation) (2014).

6. Williams B., et al. "Examination of self-directed learning readiness of paramedic undergraduates: A multi-institutional study". Journal of Nursing Education and Practice 3.2 (2012).

7. Harvey BJ., et al. "Effect of an Undergraduate Medical Curriculum on Students??? Self-Directed Learning". Academic Medicine 78.12 (2003): 1259-1265.

8. Pai K., et al. "The effectiveness of self-directed learning (SDL) for teaching physiology to first-year medical students". Australasian Medical Journal (2014): 448-453.

9. Oshea E. "Self-directed learning in nurse education: A review of the literature". Journal of Advanced Nursing 43.1 (2003): 6270 .

10. Kocaman G., et al. "A Longitudinal Analysis of the Self-Directed Learning Readiness Level of Nursing Students Enrolled in a Problem-Based Curriculum". Journal of Nursing Education 48.5 (2009): 286-290.

11. Huynh D., et al. "The Impact of Advanced Pharmacy Practice Experiences on Students Readiness for Self-directed Learning". American Journal of Pharmaceutical Education 73.4 (2009): 65.

12. Behar-Horenstein LS., et al. "An Initial Validation Study of the Self-Rating Scale of Self-Directed Learning for Pharmacy Education". American Journal of Pharmaceutical Education 82.3 (2018): 6251.

13. Premkumar K., et al. "Changes in Self-Directed Learning Readiness in Dental Students: A Mixed-Methods Study". Journal of Dental Education 78.6 (2014): 934-943.

14. Prabjanee D and Inthachot M. "Self-directed Learning Readiness of College Students in Thailand". Journal of Educational Research and Innovation 2.1 (2013).
15. Douglass C and Morris SR. "Student perspectives on selfdirected learning". Journal of the Scholarship of Teaching and Learning 14.1 (2014): 13.

16. Guglielmino LM. "Development of the self-directed learning readiness scale". (Doctoral dissertation) (1978).

17. Merriam SB., et al. "Learning in Adulthood: A Comprehensive Guide”. San Francisco: Jossey-Bass (2007).

18. Alfaifi MS. "Self-directed Learning Readiness among Undergraduate Students at Saudi Electronic University in Saudi Arabia". (Doctoral dissertation, University of South Florida) (2016).

19. Adenuga BO. "Self-directed learning readiness and learning style preferences of adult learners". (Doctoral dissertation) (1989).

20. Chen YF., et al. "Explore the relationships among demography, personality traits and self-directed learning". Journal of Human Resources and Adult Learning 2 (2006): 141-150.

21. Madhavi KV and Madhavi BD. "Readiness for self-directed learning among undergraduate medical students of Andhra Medical College, Visakhapatnam". International Journal of Community Medicine and Public Health 4.8 (2017): 2836.

22. Aly M., et al. "Instructional multimedia programs for self-directed learning in undergraduate and postgraduate training in orthodontics". European Journal of Dental Education 7.1 (2003): 20-26.

23. Said AB., et al. "Examination of Self-Directed Learning Readiness among Baccalaureate Nursing Students in Peshawar Pakistan". International Journal of Innovative Research and Development 4.2 (2015): 257-262.

24. Slater CE., et al. "Explaining variance in self-directed learning readiness of first year students in health professional programs". BMC Medical Education 17.1 (2017).

\section{Assets from publication with us}

- Prompt Acknowledgement after receiving the article

- Thorough Double blinded peer review

- Rapid Publication

- Issue of Publication Certificate

- High visibility of your Published work

Website: https://www.actascientific.com/

Submit Article: https://www.actascientific.com/submission.php Email us: editor@actascientific.com

Contact us: +919182824667 